\title{
Measurement of Ozone Over the Organ Mountains, New Mexico
}

\author{
By Ralph Stair
}

\begin{abstract}
This paper gives data on the total amount of ozone above the Organ Mountains at White Sands Proving Grounds in New Mexico from June 29, to July 4, 1947, as determined from ultraviolet measurements by a phototube and filter method. The measurements indicate ozone in the stratosphere in amount equivalent to a layer of about $0.21 \mathrm{~cm}$ thickness at normal temperature and pressure, which is in good agreement with determinations by others for the same latitude and season of the year.

The total ozone value and the solar-energy curve in the region of short ultraviolet wavelengths outside the earth's atmosphere check closely with previous work with the same instruments at Mount Evans, Colo., in 1936 and 1938.
\end{abstract}

\section{Introduction}

The measurements recorded in this paper of the total amount of ozone in the stratosphere by a phototube and filter method developed at this Bureau were made at the request of and under the sponsorship of the Naval Research Laboratory as a check upon their methods employed in V-2 rocket experiments at White Sands Proving Ground, New Mex. They were planned as a check on a flight scheduled for July 3, 1947. Although the $\mathrm{V}-2$ rocket misfired, the phototube measurements were carried through as planned from June 29 to July 4, inclusive, and the data reduced in a manner similar to that employed in the previous work at Mount Evans, Colo., in 1936 and $1938[1]{ }^{1}$

It is a well-known fact that the total amount of ozone varies from time to time, but at present little is known about any possible relationship between this variation and weather conditions, except in the instance of seasonal variations $[2,6]$ and that different types of air masses show variations that are associated with their origin or movement $[3,8]$. Variations in short ultraviolet solar energy emission also produce changes in total ozone value that fluctuates from hour to hour or from day to day. Such fluctuations may

\footnotetext{
1 Figures in brackets indicate the literature references at the end of this paper.
}

account for or be associated with "ozone cloud" effects $[4,5]$ observed by other investigators.

The method employed in this work involves the use of titanium phototubes sensitive to radiation of about $3,400 \mathrm{~A}$ (angstroms) and shorter wavelengths and filters with transmittances beginning at 2,900 to $3,100 \mathrm{~A}$ and increasing with wavelength. Ozone is strongly absorbing below about $3,200 \mathrm{~A}$. If one of the phototubes is exposed to radiation of a particular spectral distribution and intensity, it will give a measurable response. If one of the filters is now interposed, the response is reduced. The ratio of the response with the filter in place to that without it will be called the "transmittance", or "filter transmittance" and will be expressed in percentage. ${ }^{2}$ The transmittance of the filter is independent of the radiant flux density but is dependent on its spectral distribution. The interposition of ozone in sunlight greatly changes its spectral distribution in the region to which the phototube is sensitive; hence, changes in the quantity of ozone traversed cause changes in the transmittance subject to observation. If we knew the

\footnotetext{
2 It is hoped that the term "transmittance" of the filter as defined here, which is a function of the sensitivity of the phototube to each wavelength as well as the characteristics of the filter, will not be confused with "transmittance" also used in this paper in the ordinary sense, in which it is independent of the receiver beyond the filter. The term holotransmittance recently suggested by Van Lear [23] might be used. Certainly there is need for some prefix to properly signify this type of "transmittance."
} 
spectral distribution of the solar radiation, the effect of a specified quantity of ozone on transmittance of a given filter in combination with a given phototube could be calculated or, in reverse, the quantity of ozone could be determined from a single observed transmittance of the filter.

The amount of ozone traversed by sunlight that reaches the earth's surface depends on the quantity of ozone in the atmosphere and on the direction of the light. The second effect will be referred to as that of the "air mass" and represented by $M{ }^{3}$ The air mass is nearly proportional to the secant of the angle the sun's rays make with the earth's surface.

As the sunlight unaffected by ozone is not available for direct observation, its spectral distribution must be deduced from observations made at the earth's surface. To explain in principle how this can be done, it should be pointed out first that from any spectral distribution that might be assumed for sunlight and the observed transmittance of a certain combination of filter and phototube, a quantity of ozone in the atmosphere may be calculated. If a simultaneous observation is made with another combination of instruments having different spectral absorptions and sensitivities, a quantity of ozone can likewise be calculated. If the instruments have been correctly calibrated and if the two values obtained for the ozone do not agree, something is wrong with the assumed spectral distribution of the sunlight. The correct distribution should give the same result for ozone with any combination of detecting equipment. Also, there is reason to believe that, on the average, there is little change in the ozone content of the atmosphere with time of day, but because of the change of air mass there is a large easily calculated change in mass of ozone traversed by the sunlight from morning to noon and from noon to evening. If, on the average, the changes in the effect attributed to ozone correspond to changes in air mass without change in the atmospheric content of ozone, there is evidence that the spectral distribution curve of the sunlight is correct. If, in general, the computed ozone content shifts with changing air mass, the spectral distribution curve of the sunlight may be assumed to be in error. By a

\footnotetext{
${ }^{3}$ Only relative values of $M$ will be used. For sunlight outside the earth's atmosphere $M=0$. For vertical sunlight, never available outside the tropics, $M=1$. The reader must not confuse this use of the term "air mass" with the same term used to designate air of a particular origin, temperature, or other property.
}

process of trial and error, approximate spectral distribution curves initially assumed have been modified to make all observed data reasonably consistent. The unavoidably complicated processes employed in this derivation have been more fully explained in reference [1].

In either the method employed in this work, wherein comparisons are made between the relative intensities of different spectral regions, or with the photographic or photoelectric method, wherein two single wavelengths in the solar spectrum are isolated and from their relative intensities the absorption by ozone and hence the total amount is calculated, it is impossible to separate changes in the spectral quality of solar radiation from true ozone changes. However, when the measurements are made at the earth's surface, radiated energy of wavelengths shorter than 3,000 A has little or no effect upon the calculated results when either method is employed, as it is almost completely absorbed even for low air masses on a mountain top. Hence it is believed that changes in solar emission may be neglected without making a serious error in the determination of the total amount of ozone.

In an earlier paper [9] it was first pointed out in 1937 by the author that it should be possible to follow the ozone cycle through the year and from year to year by means of phototube and filter measurements. At that time, suitable means and methods of accurately calibrating phototubes and filters for this purpose were not readily available. Nevertheless, with an improvised standard source of ultraviolet radiation in the form of a Mazda CX lamp, a forward step was made in 1939 [1] in the evaluation of ultraviolet solar radiation data obtained at Mount Evans, Colorado, in thesummers of 1936 and 1938. With the development of ultraviolet standards in the form of tungsten-inquartz lamps $[10,11]$, the problem of accurately calibrating ultraviolet phototubes has been immeasurably simplified. Furthermore, the development of the Beckman [17, 18] and other ultraviolet spectrophotometers has made possible accurate determinations of filter transmittance within the Huggins ozone absorption region of 2,900 to $3,400 \mathrm{~A}$.

Recently a preliminary survey was made of the possibility of using a recording infrared spectrometer to measure the total amount of ozone by the change in intensity of the absorption band at 
9.7 microns. This method shows some promise, but because of temperature and pressure effects $[12,13]$ at this wavelength and because of interference of water vapor absorption on days of high humidity, it will probably not replace the use of the Huggins band in the ultraviolet. Furthermore, difficulties involved in keeping a proper image of the sun on the spectrometer-entrant slit rule in favor of the simple phototube and filter method employed in the present investigation.

\section{Phototubes and Filters}

In the work at San Augustine pass in the Organ Mountains, N. Mex., the same two titanium phototubes (Nos. 2 and 6) and the same filters (Corex D; Nillite; Barium Flint, $1 \mathrm{~mm}$; and Barium Flint, $3 \mathrm{~mm}$ ) were employed as at Mount Evans, Colorado [1] in 1936. The relative spectral responses of the phototubes and the transmittance of the filters are given in figure 1 . It is to be noted that the relative spectral response of phototube $\mathrm{Ti}-2$ has remained closely the same as it was in 1936. However, that for phototube Ti-6 has undergone a marked change during the years so that now it is more sensitive to longer wavelengths than is the case for Ti-2. A change of this type is unimportant so long as it does not occur between calibration and use of the phototube.

The original calibration of the relative spectral response of these phototubes is described in detail

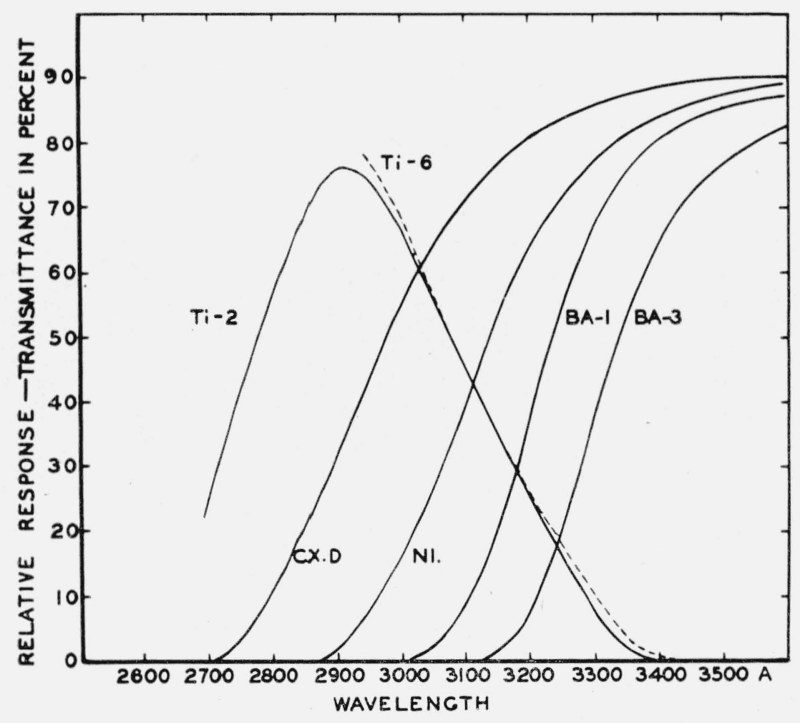

FigURE 1. Graphs showing the relative spectral response curves for the two titanium phototubes; also the spectral transmittances of the four filters. in the previous report [1]. Supplementary calibrations have been made by using the spectroradiometer and standards of continuous spectral ultraviolet radiation $[10,11]$ from time to time. A new spectral calibration was made for phototube Ti-6 following its use in this work.

\section{Ultraviolet Meter}

The phototube current was amplified by means of a portable balanced-tube direct current amplifier and read on a 0 to 15 microampere Weston Model 440 meter. This amplifier was batteryoperated and of such dimensions that it was easily transported to the Organ Mountain station (elevation 5,640 ft) at the San Augustine pass. Figure 2 shows this amplifier, and figure 3 an

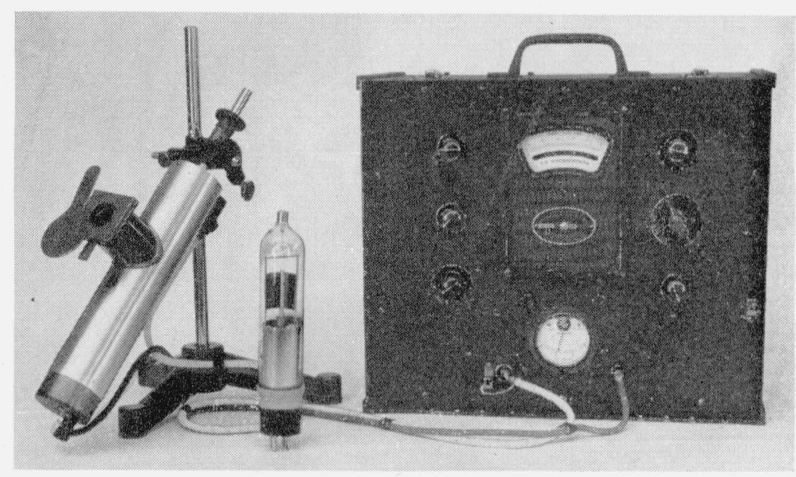

Figure 2. Ultraviolet meter, titanium phototube, and phototube mounting.

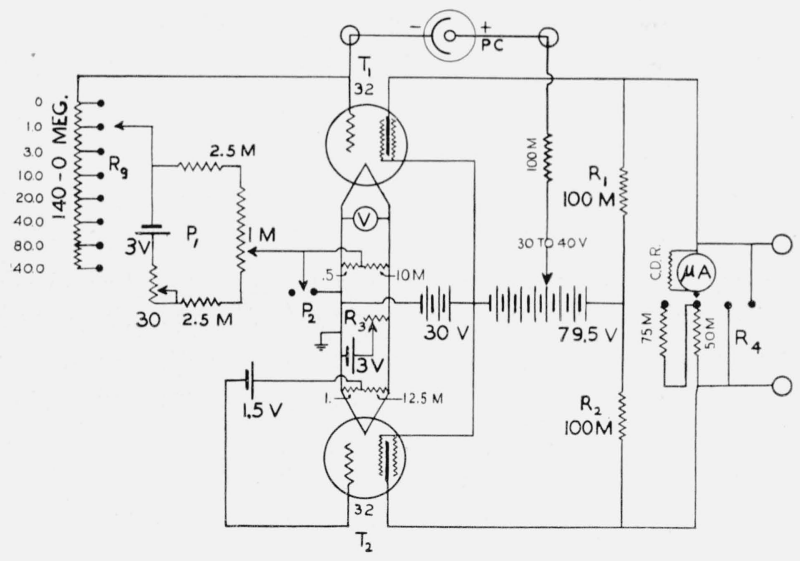

Figure 3. Electrical circuit of the ultraviolet meter.

electric circuit of the amplifier. Complete details covering the construction and operation of the amplifier are given in the previous publication [1]. Careful construction of this instrument through the use of high-grade parts and nonmicrophonic 
balanced tubes enabled the operator to obtain measurements in strong winds wherein the instrument was jostled about on its table.

\section{Method for Evaluating the Amount of Ozone}

Using the four filters whose transmittances are given in figure 1 , measurements were alternately made with the two titanium phototubes. The total percentage transmittances of these filters for sunlight were calculated and plotted as a function of air mass (see figs. 5 and 6 ).

The determination of the solar air mass as a function of standard time at a station is a rather detailed operation that must be performed before it is possible to interpret the filter-transmittance data intelligently. From the yearly issue of the American Ephemeris and Nautical Almanac [19], the equation of time may be obtained. From the longitude of the observing station, a longitude time correction is calculated. For San Augustine Pass, this correction was about $-6 \mathrm{~min}$ and 11 sec (pass longitude $109^{\circ} 32^{\prime} 45^{\prime \prime} \mathrm{W}$ ). From the American Ephemeris and Nautical Almanac for 1947 , the equation of time correction was found to be $-3 \mathrm{~min}$ and $48 \mathrm{sec}$ (for July 2 ). The sum of these two corrections is $-9 \mathrm{~min}$ and $59 \mathrm{sec}$. For the other days the hour angle corrections ranged from $-9 \mathrm{~min}$ and $23 \mathrm{sec}$ to $-10 \mathrm{~min}$ and 21 sec.

During the period of observations, June 29 to July 4, the solar declination ranged from $23^{\circ} 15^{\prime} 23^{\prime \prime}$ to $22^{\circ} 54^{\prime} 59^{\prime \prime}$. The latitude of the San Augustine Pass is approximately $32^{\circ} 27^{\prime} 35^{\prime \prime} \mathrm{N} \quad\left(32.46^{\circ}\right.$ North). From Ball's altitude tables [20], in which true solar altitudes for even degree values of latitude are tabulated for hour angle intervals of $4 \mathrm{~min}$, a new table for $32.46^{\circ}$ was calculated by interpolation. These data were plotted using as ordinate and absissa, true solar altitude and solar declination, respectively. From this set of curves, true solar altitudes (for 4-min intervals throughout the day) were obtained for the solar declinations corresponding to the days on which observations were made. Finally, these true solar altitudes were translated into solar air masses (air mass equals approximately the secant of the sun's zenith distance) for 4-min intervals on the days on which observations were made, and plotted as a function of mountain standard time, hour angle correction being made for longitude and equation of time.

In order to obtain a measure of the amount of ozone at the time of the observations, a solar energy curve outside the earth's atmosphere is assumed. For this, the curve obtained in the Mount Evans work [1] (S. and H. 1936-38) was employed as an approximation for preliminary calculations. Starting with this spectral energy curve, and by a process of arithmetical integration (using 20 angstroms as a unit) a set of transmittance curves for the four filters and two phototubes, as a function of solar air mass was calculated. For these calculations, the Fabry and Buisson [15] transmittance coefficients for ozone and the Rayleigh scattering (atmospheric transmittance) coefficients as used by O'Brien [16] in the reduction of the stratosphere balloon data (Explorer $I$ and $I I$ ) have been used. Some of the ozone and scattering transmittance curves are reproduced in figure 4 . Next, changes were made in the original solar curve and recalculations performed to give closer agreement between the slopes of the calculated curves and the observed data. Hence by trial and error the shape of the solar energy curve outside the earth's atmosphere is determined.

This method is illustrated by an example in table 1, which gives all the steps in the determination of one point (air mass $=1.0$ ) on each of the calculated $(0.20 \mathrm{~cm})$ ozone curves for phototube

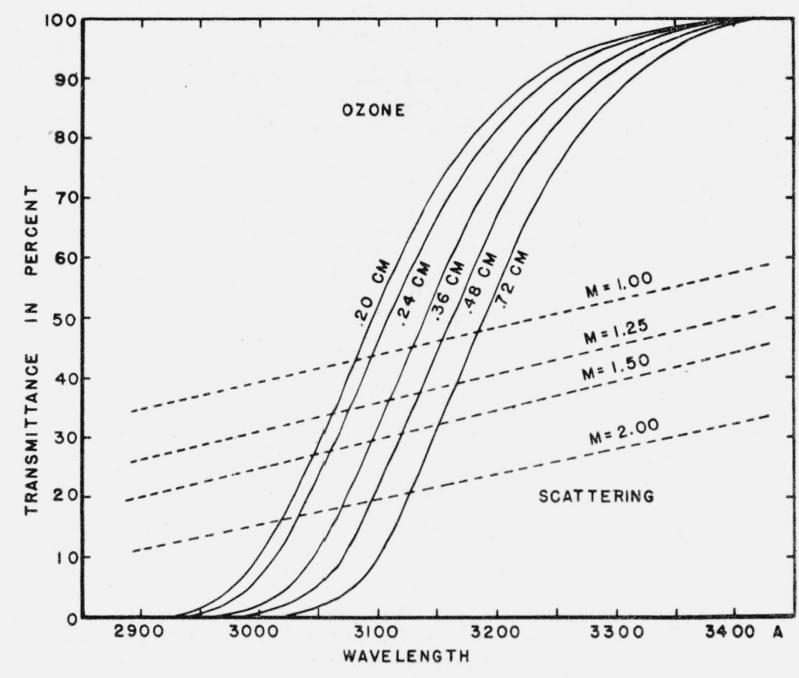

FIgURE 4. Graphs showing the spectral transmittance of the atmosphere in terms of molecular (Rayleigh) scattering and ozone absorption. 
TABLE 1. Method employed in the calculation of ozone values

This example includes a single set of data for phototube Ti-2 for air mass $M=1.00$ and an ozone value of $0.20 \mathrm{~cm}$ ntp.

\begin{tabular}{|c|c|c|c|c|c|c|c|c|c|c|c|c|c|c|}
\hline $\begin{array}{l}\text { Center of wave- } \\
\text { length interval }\end{array}$ & $\begin{array}{c}\text { Relative } \\
\text { spectral } \\
\text { energy } \\
M=0\end{array}$ & $\begin{array}{c}\text { Scatter- } \\
\text { ing } \\
\text { trans- } \\
\text { mit- } \\
\text { tance } \\
M=1.00\end{array}$ & $\begin{array}{c}\text { Trans- } \\
\text { mit- } \\
\text { tance } \\
0.2 \mathrm{cmO}_{3}\end{array}$ & $\begin{array}{l}\text { Column } \\
2 \times 3 \times 4 \\
\text { relative } \\
\text { energy } \\
M=1.00\end{array}$ & $\begin{array}{c}\text { Relative } \\
\text { response } \\
\text { photo- } \\
\text { tube } \\
\text { Ti-2 }\end{array}$ & $\begin{array}{l}\text { Column } \\
5 \times 6 \text { in- } \\
\text { tegrated } \\
\text { response }\end{array}$ & $\begin{array}{c}\text { Trans- } \\
\text { mit- } \\
\text { tance } \\
\text { Corex } \\
\text { D }\end{array}$ & $\begin{array}{l}\text { Column } \\
7 \times 8 \text { in- } \\
\text { tegrated } \\
\text { response }\end{array}$ & $\begin{array}{l}\text { Trans- } \\
\text { mit- } \\
\text { tance } \\
\text { Nillite }\end{array}$ & $\begin{array}{c}\text { Column } \\
7 \times 10 \\
\text { inte- } \\
\text { grated } \\
\text { response }\end{array}$ & $\begin{array}{l}\text { Trans- } \\
\text { mit- } \\
\text { tance } \\
\text { Ba-1 }\end{array}$ & $\begin{array}{c}\text { Column } \\
7 \times 12 \\
\text { inte- } \\
\text { grated } \\
\text { response }\end{array}$ & $\begin{array}{l}\text { Trans- } \\
\text { mit- } \\
\text { tance } \\
\text { Ba-3 }\end{array}$ & $\begin{array}{l}\text { Column } \\
7 \times 14 \text { in- } \\
\text { tegrated } \\
\text { response }\end{array}$ \\
\hline 1 & 2 & 3 & 4 & 5 & 6 & 7 & 8 & 9 & 10 & 11 & 12 & 13 & 14 & 15 \\
\hline $\begin{array}{c}A \\
2,900\end{array}$ & 15 & 0.350 & 0.0001 & ...... & 0.76 & .... & 0.324 & .... & 0.014 & -... & -.... & -... & -...-. & -... \\
\hline 20 & 30 & .360 & .001 & 0.01 & .76 & 0.01 & .370 & .... & .039 & .... & ...... & -... & -..... & -... \\
\hline 40 & 47 & .370 & .006 & .10 & .75 & .08 & .420 & 0.03 & .070 & 0.01 & ...... & -.... & -.-.- & .... \\
\hline 60 & 56.5 & .379 & .0195 & .42 & .73 & .31 & .468 & .14 & .100 & .03 & -.... & -... & -...-. & -..- \\
\hline 80 & 58 & .388 & .055 & 1. 24 & .70 & .87 & .514 & .45 & .132 & .11 & - .... & -... & -...- & -... \\
\hline 3,000 & 58.5 & .397 & .106 & 2. 46 & .66 & 1. 62 & .555 & .90 & .165 & .27 & -...-. & -... & -...-. & -...- \\
\hline 20 & 55.5 & .406 & .170 & 3. 83 & .62 & 2. 37 & .595 & 1. 41 & .204 & .48 & 0.003 & 0.01 & -... & .... \\
\hline 40 & 52 & .415 & .247 & 5. 33 & .58 & 3. 09 & .630 & 1. 95 & .246 & .76 & .017 & .05 & -...- & -... \\
\hline 60 & 50 . & .424 & .340 & 7. 21 & .53 & 3. 82 & .660 & 2. 52 & .293 & 1. 12 & .035 & .13 & -.... & .... \\
\hline 80 & 49.5 & .433 & .435 & 9. 32 & .49 & 4. 57 & .690 & 3. 15 & .343 & 1. 57 & .060 & .27 & -.... & -... \\
\hline 3,100 & 49 & .442 & .526 & 11. 39 & .45 & 5. 13 & .717 & 3. 68 & .398 & 2. 04 & .090 & .46 & ...... & .... \\
\hline 20 & 49.5 & .451 & .613 & 13,68 & .405 & 5. 54 & .742 & 4. 11 & .457 & 2. 53 & .133 & .74 & 0.001 & 0.01 \\
\hline 40 & 52 & .460 & .684 & 16. 36 & .360 & 5. 89 & .763 & 4. 49 & .514 & 3. 03 & .180 & 1.06 & .008 & .05 \\
\hline 60 & 56 & .469 & .747 & 19. 62 & .320 & 6.28 & .779 & 4. 89 & .563 & 3. 54 & .237 & 1. 49 & .023 & .14 \\
\hline 80 & 59 & .478 & .800 & 22. 56 & .285 & 6.43 & .793 & 5. 10 & .605 & 3. 89 & .310 & 1. 99 & .042 & .27 \\
\hline 3,200 & 64 & .487 & .848 & 26. 43 & .245 & 6. 48 & .807 & 5. 23 & .645 & 4. 18 & .380 & 2. 46 & .075 & .49 \\
\hline 20 & 74 & .496 & .884 & 32.45 & .210 & 6.81 & .818 & 5. 57 & .680 & 4. 63 & .455 & 3. 10 & .127 & .86 \\
\hline 40 & 88 & .505 & .914 & 40.62 & .175 & 7. 11 & .830 & 5. 90 & .710 & 5. 05 & .526 & 3. 74 & .190 & 1.35 \\
\hline 60 & 94 & .514 & .936 & 45. 22 & .140 & 6. 33 & .842 & 5. 33 & .737 & 4. 67 & .580 & 3. 67 & .250 & 1. 58 \\
\hline 80 & 86 & .523 & .951 & 47.75 & .105 & 5. 01 & .850 & 4. 26 & .757 & 3. 79 & .630 & 3. 16 & .315 & 1. 58 \\
\hline 3,300 & 98 & .532 & .963 & 50. 21 & .075 & 3. 77 & .857 & 3. 23 & .775 & 2. 92 & .670 & 2. 53 & .380 & 1. 43 \\
\hline 20 & 99 & .541 & .973 & 52.11 & .045 & 2. 34 & .865 & 2. 02 & .792 & 1. 85 & .703 & 1. 65 & .440 & 1. 03 \\
\hline 40 & 99 & .550 & .980 & 53. 36 & .023 & 1. 23 & .873 & 1.07 & .805 & 0. 99 & .736 & 0.91 & .505 & 0.62 \\
\hline 60 & $6 y$ & .559 & .987 & 54. 62 & .010 & 0.55 & .878 & 0.48 & .818 & .45 & .766 & .42 & .555 & .31 \\
\hline 80 & 99 & .568 & .995 & 55. 95 & .003 & .17 & .883 & .15 & .829 & .14 & .790 & .13 & .600 & .10 \\
\hline Total_. & .... & .... & -.... & ..... & .... & 85.81 & .... & 66.06 & .... & 48.05 & -... & 27.97 & -... & 9.82 \\
\hline $\begin{array}{c}\text { Percentage } \\
\text { trans. } \\
\text { mittance- }\end{array}$ & -... & -... & -.... & -..... & -... & -... & -... & 77.0 & -... & 56.0 & -... & 32.6 & -..- & 11.4 \\
\hline
\end{tabular}

Ti-2. In this table, column 1 gives the center of each 20-A wavelength interval. Column 2 gives the relative spectral energy distribution assumed for $M=0$ that is, outside the earth's atmosphere. in column 3 are given transmittance values for air mass 1.0 when scattering only is taken into account. Similarly, transmittance values for 0.20 cm ozone (the ozone curve being calculated) are given in column 4 .

The product of columns 2,3 , and 4 gives column 5 which represents, therefore, the relative spectral solar energy curve for air mass 1.00 and $0.20 \mathrm{~cm}$ ozone. In column 6 , the relative spectral response values (for equal energy) for phototube Ti-2 are tabulated. The product (column 7) of columns 5 and 6 gives, consequently, the calculated integral response of the phototube for solar radiation, air mass 1.00 , ozone value $0.20 \mathrm{~cm}$. Columns 8,10 , 12 , and 14 give the spectral transmittance of the four filters and columns 9, 11, 13, and 15 the integrated photoelectric responses through the four filters, respectively. From the sums of the integrated values for the phototube alone and through the several filters, the calculated filter percentage transmittances are obtained directly as ratios. In this case, the four values are 77.0, $56.0,32.6$, and 11.4 , and are plotted as large circles in figure 5 at air mass 1.00 . Other points on the same and on other curves for different assumed amounts of ozone are similarly calculated.

Although the preliminary calibrations and calculations for a particular phototube and set of filters are quite complicated, when they are once made it is simple from this set of curves to deter- 


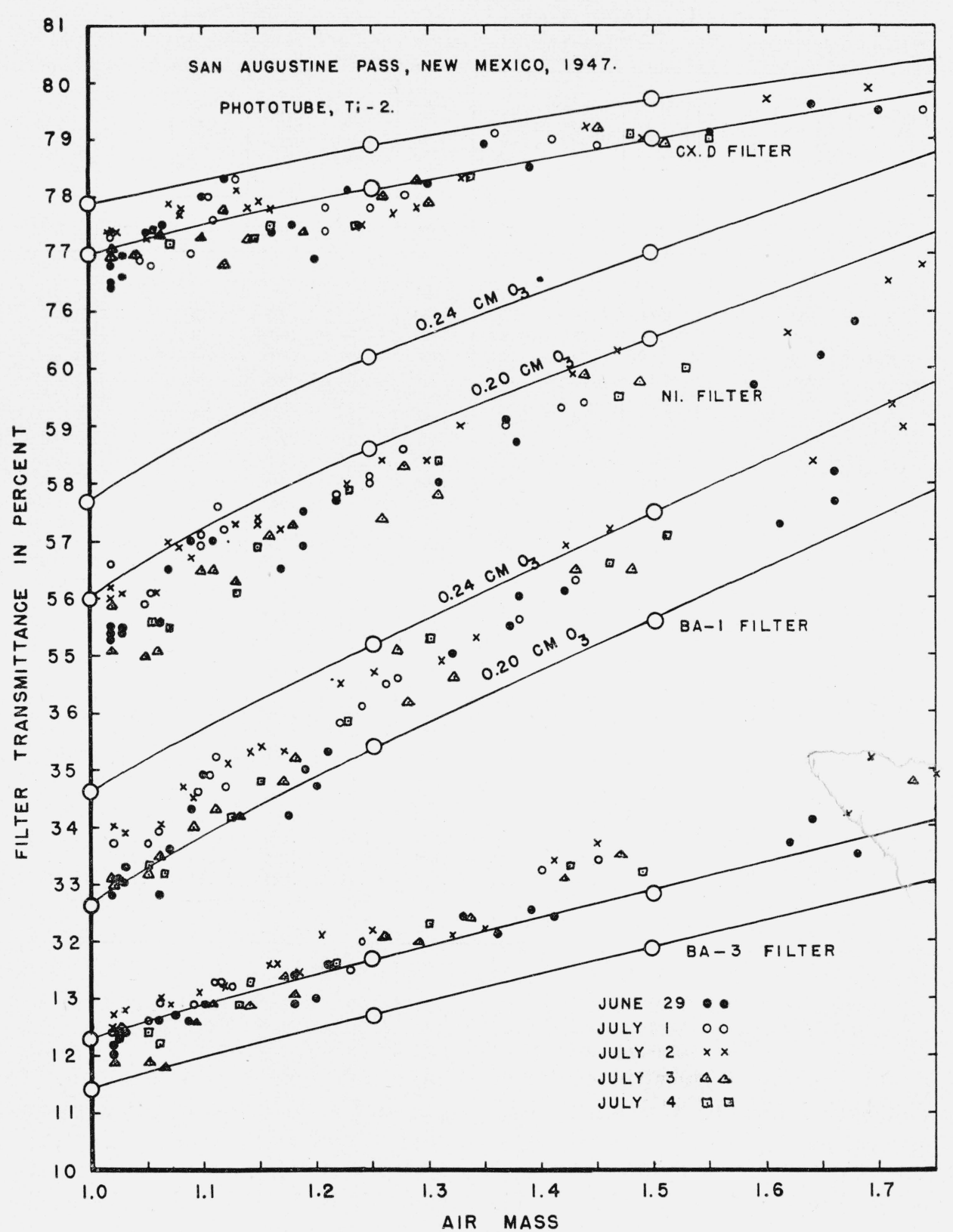

FIGURE 5. Graphs showing the amount of ozone in the stratosphere, based on observations with titanium phototube No. 2; calculations based on the 1947 Stair solar energy curve for air mass, $m=0$.

mine the ozone value from measurements with a single filter within a few minutes time. This is a highly important factor should such measurements become useful for weather forecasting purposes.

\section{Amount of Ozone Over the Organ Mountains on June 29 to July 4, 1947}

In figures 5 and 6 are represented the observed data and the calculated effects of assumed amounts of ozone above the San Augustine Pass in the Organ Mountains of New Mexico for the period of June 29 to July 4, 1947. Although the data show some scatter, due principally to thin clouds and haze which at times covered the area of the sky surrounding the sun, they show distinct changes in the total ozone value from day to day. The values for June 29 are near the mean value for all the measurements, whereas those for July 1 and 2 are higher and those for July 3 and 4 are lower 
than this mean value. These changes are no doubt associated with air mass changes for this area.

On June 29, according to the Weather Bureau reports, this area was covered by a layer of cold continental tropical air centered over the lower Rocky Mountain regions of New Mexico and Arizona. During most of the day a medium strong wind (probably 20 to 25 miles an hour) was blowing from the west. A quasi-stationary front existed in southern Colorado between a polar maritime air mass and a mass of cold continental polar air, which was moving into the northern part of the United States from Canada.

By the following day, June 30, a large mass of polar continental air had spread over the northern part of the country. There was practically no surface air movement (wind) at White Sands, and the sky was about one-half clouded over throughout the day, with clouds over the sun most of the

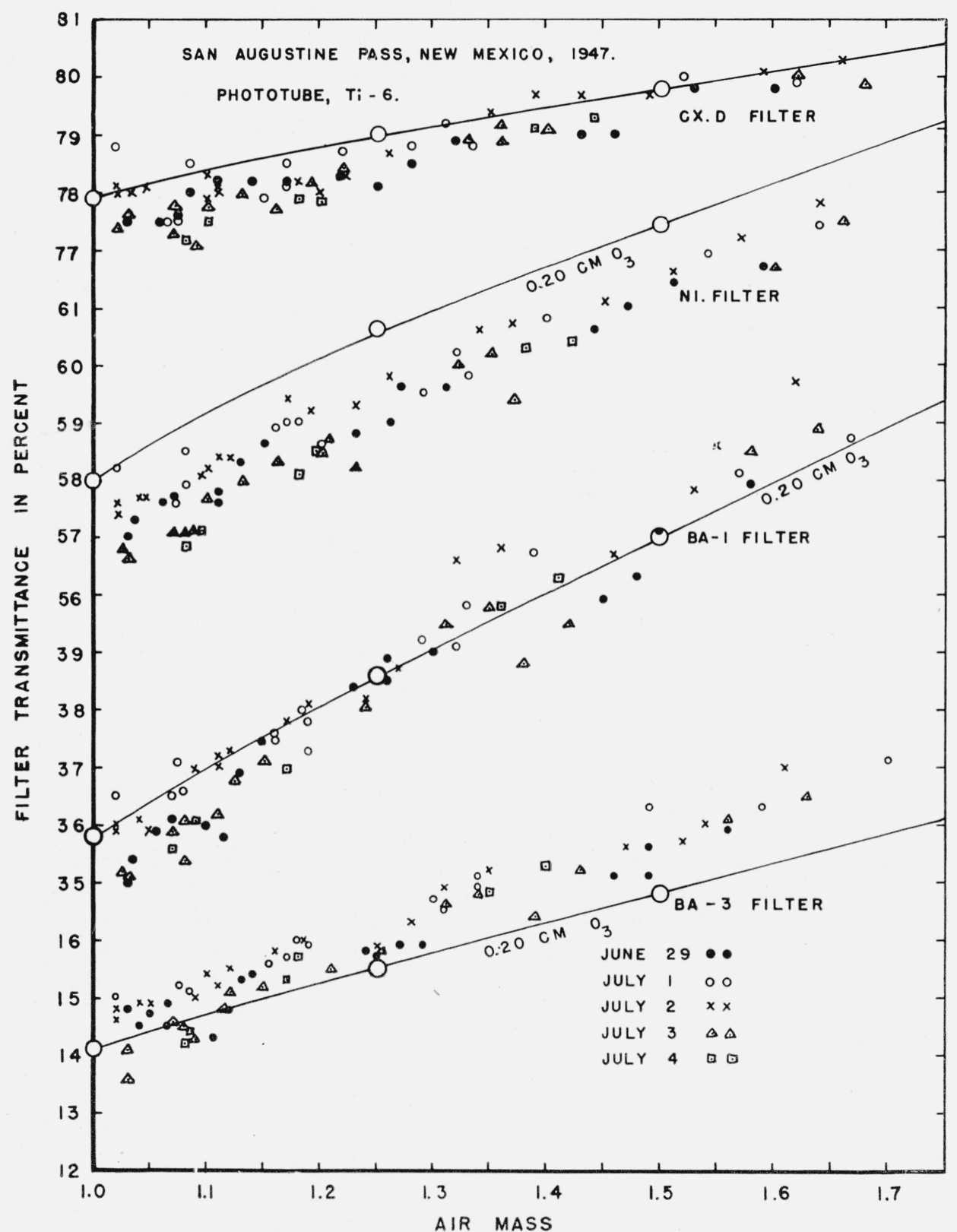

FIGURE 6. Graphs showing the amount of ozone in the stratosphere, based on observations with titanium phototube No. 6; calculations based on the 1947 Stair solar energy curve for air mass, $m=0$ 
time as would be expected with the air mass front moring in from the north. Because of these clouds no ozone measurements could be made.

By the morning of July 1, the mass front had passed to the south of White Sands leaving the area blanketed with polar continental air at lower levels, with some tropical maritime above and continental tropical air at still higher levels. The higher ozone value observed is in agreement with other observations $[2,6,7]$ showing greater amounts of ozone at higher latitudes or associated with polar air masses. A strong wind was blowing from the east throughout the day. Except for some haze and a few clouds, the sky remained relatively clear until late afternoon when it rapidly clouded up, giving rise to several thunder showers within the area. Early in the evening there was a light shower (less than $1 / 10$ in.) over the San Augustine Pass area.

On July 2, the atmospheric conditions remained about the same as on July 1, except there were but few clouds at any time. The wind continued from the east. By this time most of the continental United States was covered by the continental air mass that had moved in from Canada. However, the San Augustine Pass area was near a large mass of tropical maritime air, which was over the greater part of Texas and was moving to the north and west.

By July 3, the air mass over San Augustine Pass was probably tropical maritime, with tropical continental aloft. There was little wind at the ground level, and more clouds in the sky, especially of the fracto-cumulus type, as illustrated in the photograph (fig. 8), which was made on this day. During most of the day these clouds were continually forming over the Organ Mountain area. Although there was a light wind, the clouds remained relatively stationary through the process of breaking up and reforming. The lower ozone value observed on this day is in keeping with the probable air mass conditions.

By July 4, the air mass was no doubt a tropical maritime air mass or of similar constitution. The wind had practically ceased to blow, and the formation of fracto-cumulus clouds so nearly covered the mountain area that measurements were discontinued about noon of this day. Low values of ozone were to be expected and were observed on this day.

The mean value of ozone when all of these measurements are considered appears to be 0.20 and $0.21 \mathrm{~cm}$ ntp. The data obtained with phototube Ti-2 indicate the higher value. As the spectral response of this phototube has remained constant over the past 12 years following its original calibration, greater weight should probably be given to this higher value.

In obtaining the mean value of $0.21 \mathrm{~cm} \mathrm{ntp}$, greatest weight was given to the data for filter $\mathrm{Ba}-1$ because its transmittance was within the range of greatest sensitivity to ozone changes. Furthermore, greater weight was given to the smaller air mass values, as the effects of haze, dust, and clouds were less near the noon hour on most of the days on which the observations were made.

The fact that there is not perfect agreement for the calculated amount of ozone between the measurements with the four filters for each of the two phototubes (eight independent determinations) is not disconcerting. The discrepancies are of the order of the errors in the measurements of the spectral transmittances of the filters or of the relative spectral responses of the phototubes. Filters having transmittances less than 30 percent or more than 70 percent (for sunlight) should not be used for the determination of total ozone. They are included in this case mainly for their value in establishing the spectral solar energy curve and are given but little weight in the ozone determinations. Furthermore, in this case it appears that the transmittance of the $\mathrm{Ni}$ filter is out of agreement with the mean of the other three filters, indicating that its spectral transmittance may be slightly in error.

\section{Solar Energy Curve Outside the Atmosphere}

In this work it is necessary to know or else calculate the relative solar energy curve of the sun for a number of different air masses. In any case, one of these is either for air $\operatorname{mass}=0$, or else that curve may be simply calculated. In the present work, the curve for the sun outside the atmosphere as previously published by Stair and Hand [1] was used for preliminary calculations. However, as data were needed for wavelengths extending up to $3,400 \mathrm{~A}$, this curve was arbitarily extended to that wavelength.

The preliminary calculations of filter transmit- 
tance indicated that the arbitrary curve in the longer wavelengths was too high relative to the values at 3,000 to $3,200 \mathrm{~A}$. Hence adjustments were made until there was reasonable agreement between observed and calculated transmittance values for different air masses for the four filters with the two phototubes. Calculations made using a solar energy curve obtained by Hulburt [22] at an altitude of $55 \mathrm{~km}$ (above more than 99 percent of the atmospheric ozone) give an ozone value about $0.015 \mathrm{~cm}$ greater than the values indicated by the calculations illustrated in figures 5 and 6 . However, the filter transmittance indicated poorer agreement for the shape of this solar energy curve than for the one defined by the data of column 2 of table 1.

Up to this point only the relative shape of the solar energy curve has been considered. Nothing has been considered that would give it magnitude in terms of microwatts per square centimeter per unit of wavelength. That step is next. As the shape of the curve is defined by the relative values of column 2 of table 1, the magnitude of these values will now be discussed in terms of a wavelength unit of $10 \mathrm{~A}$.

First, the calibration of the ultraviolet meter for total response to a standard of ultraviolet radiation will be considered $[9,14,21]$. Two calibration constants designated $P$ and $G$ for the standard lamp and for the sun respectively are required. The method of determination of factor $P$ is given best by the presentation of the actual data of table 2. From this table, factor $P$ is found to be 5.40 for Ti-2 and 6.73 for Ti- 6 .

Next, from the relative solar data for some observed air mass, factor $G$ is obtained. In the present work the air masses 1.00 and 1.25 were employed, as curves are already calculated for these values (see table 1 ).

To obtain factor $G$ for Ti-2 and air mass 1.00, the procedure is as follows: First take an arbitrary wavelength interval, for example all wavelengths shorter than 3,210 A (see table 1). This sum is 139.96 and is found by adding all the values in column 5 for the wavelength intervals shorter than $3,220 \mathrm{~A}$. Next take the sum of all values in column 7. This is found to be 85.81. Finally, take the ratio of 139.96 to 85.81 , which is $1.63-$ designated factor $G$. The factor $G$ for $M=1.25$ was obtained in a similar manner and found to be
TABle 2. Calibration of phototubes, using standard ultraviolet lamp with a Corex D filter; calculation of factor $P$

Factor $P=38.48 \div 7.12=5.40$ for Ti- 2 .

Factor $P=39.86 \div 5.92=6.73$ for Ti- 6 .

(7.12 and 5.92 were the observed ultraviolet meter deflections when the standard lamp was used as the source of radiation).

\begin{tabular}{|c|c|c|c|c|c|}
\hline Wavelength & $\begin{array}{l}\text { Standard } \\
\text { lamp } \\
\text { energy } \\
\text { through } \\
\text { Cx. D } \\
\text { filter }\end{array}$ & $\begin{array}{c}\text { Relative } \\
\text { response, } \\
\text { Ti-2 }\end{array}$ & $\begin{array}{c}\text { Relative } \\
\text { response, } \\
\text { Ti-6 }\end{array}$ & $\begin{array}{c}\text { Energy } \\
\text { times } \\
\text { response, } \\
\text { Ti-2 }\end{array}$ & $\begin{array}{c}\text { Energy } \\
\text { times } \\
\text { response, } \\
\text { Ti-6 }\end{array}$ \\
\hline$A$ & $\mu w / \mathrm{cm}^{2}$ & & & & \\
\hline $3,340 \ldots$ & 6. 6 & 0.023 & 0.047 & 0.15 & 0.46 \\
\hline $3,132 \ldots$ & 53.3 & .380 & .385 & 20.25 & 20.52 \\
\hline $3,024 \ldots$ & 18.5 & .615 & .627 & 11.38 & 11.60 \\
\hline $2,967 \ldots$ & 7.0 & .723 & .76 & 5.06 & 5. 32 \\
\hline 2,890 & 1.8 & .75 & .85 & 1.35 & 1. 53 \\
\hline 2,804 & 0.5 & .57 & .85 & 0.29 & 0.43 \\
\hline Total. & & & & 38.48 & 39.86 \\
\hline
\end{tabular}

1.58. For phototube Ti-6, the corresponding' values were 1.45 and 1.39 .

In order to arrive at a value of total response, all the observational data obtained for air masses 1.02 to 1.30 were plotted and the values read from a smooth curve at $M=1.00$ and $M=1.25$. The mean values thus obtained were 16.0 and 12.1 microamperes for phototube Ti-2, and 14.3 and and 11.0 for phototube Ti-6 for air masses $M=1.00$ and $M=1.25$, respectively.

From the above information, the total energy may be calculated for the two phototubes for the two air masses $M=1.00$ and $M=1.25$. These were as follows: (The factor 2 entering into each equation is an instrument scale factor, U. V. Q. is used as a symbol to denote the total radiant flux density within the selected spectral region.)

\section{For Ti-2}

U. V. Q. $(M=1.00)=16.0 \times 2 \times 5.40 \times 1.63=$ $282 \mu \mathrm{w} / \mathrm{cm}^{2}$.

U. V. Q. $(M=1.25)=12.1 \times 2 \times 5.40 \times 1.55=$ $206 \mu \mathrm{w} / \mathrm{cm}^{2}$.

$$
\text { For Ti-6 }
$$

U. V. Q. $(M=1.00)=14.60 \times 2 \times 6.73 \times 1.45=$ $285 \mu \mathrm{w} / \mathrm{cm}^{2}$.

U. V. Q. $(M=1.25)=11.30 \times 2 \times 6.73 \times 1.39=$ $211 \mu \mathrm{W} / \mathrm{cm}^{2}$. 
From these the mean values of the total solar energy for the two air masses, $M=1.00$ and $M=$ 1.25 , becomes 283 and $209 \mu \mathrm{w} / \mathrm{cm}^{2}$ for wavelengths shorter than $3,210 \mathrm{~A}$.

If now the above information is applied to the data of table 1, an intensity factor may be found which, when multiplied by the relative values of solar energy in column 2, will give the absolute spectral solar energy outside the earth's atmosphere. This factor is found as follows (see table 1). Again take the sum of all values in column 5 for the same wavelength interval as used before, namely shorter than $3,210 \mathrm{~A}$. This value was found to be 139.96. For phototube Ti-2 we have

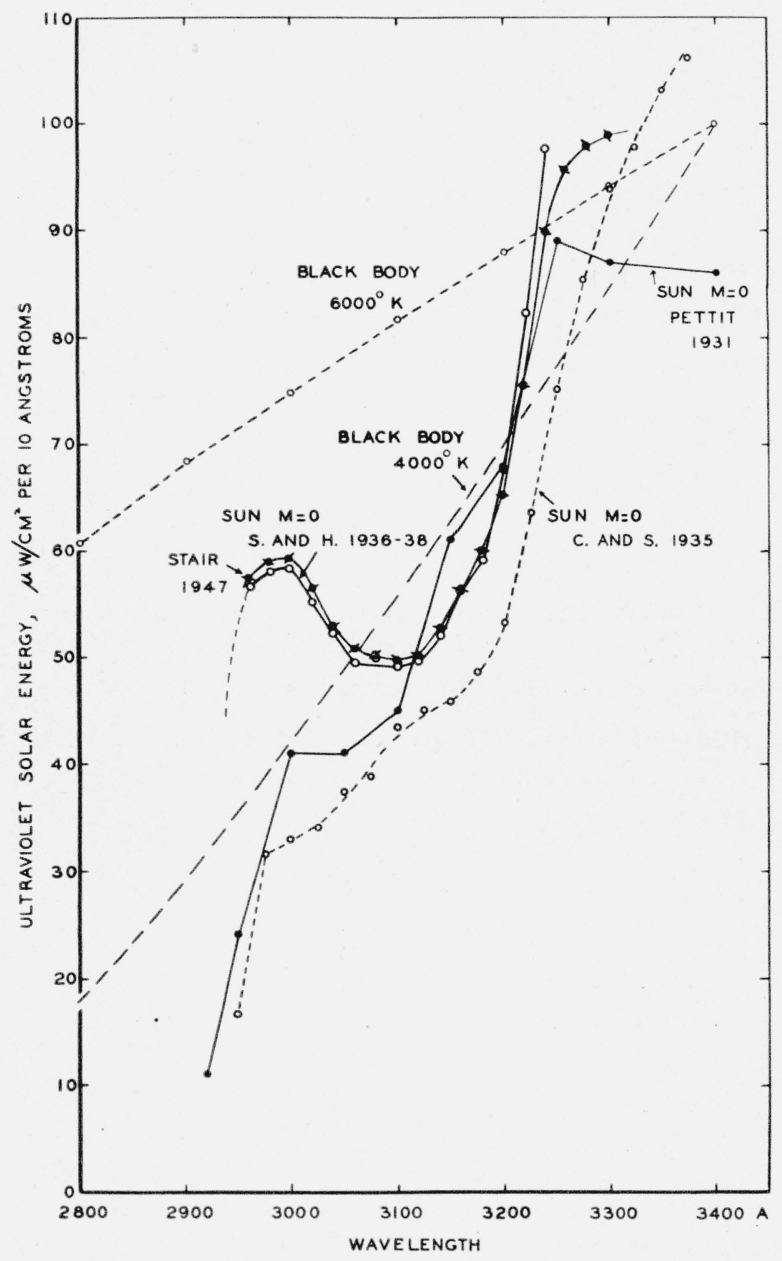

FIGURE 7. Distribution of energy in the eatreme ultraviolet of the solar spectrum.

The Stair curve is the average of determinations with two phototuhes at Organ Mountain. The S \& H (Stair and Hand) curve is the average of determinations at Mount Evans, Colorado with four phototubes. Curves by other observers and for a black body (on relative seales) are given for com. parative purposes.
$282 \div 139.96=2.01$ for $M=1.00$, and similarly, $206 \div 101.59=2.03$ for $M=1.25$. For phototube Ti- 6 the corresponding data are $285 \div 139.96=2.04$ for $M=1.00$, and similarly, $211 \div 101.59=2.08$ for $M=1.25$. The mean of these four values (2.04) is the intensity factor. However, as the data are to be evaluated in terms of a wavelength interval of $10 \mathrm{~A}$ (20 $\mathrm{A}$ have been used in the table), this factor becomes 1.02 as a multiplying factor to be applied to the data of column 2 of table 1 to give the solar energy curve outside the earth's atmosphere in microwatts per square centimeter per 10-A interval of wavelength. The values thus obtained are illustrated in figure 7 .

The very close agreement in absolute units between the solar curve obtained from this work and that obtained at Mount Evans is encouraging and is much better than was expected. The fact that the two phototubes gave values in close agreement, although one of them had changed in both total and spectral response since it was employed at Mount Evans, indicates that with careful calibration this method is both reliable and practical for the measurement of total ultraviolet solar radiation.

\section{Conclusions}

The preliminary calibrations and calculations for a particular phototube and filters for a particular station are complicated, but when these are once made it is possible, from a set of curves, to determine the total ozone value from measurements with a single filter within a few minutes. It is more efficient and accurate to use a filter having a total integrated transmittance near 50 percent, as the transmittance of a filter in that range is most sensitive to ozone changes when used with a phototube of the type employed in this work. Should ozone measurements of this type become useful for weather forecasting purposes, this method appears practical for use at an extended group of stations, with calibrations performed at some central station.

The total amounts of ozone determined for the San Augustine pass in the Organ Mountains are in agreement with other determinations for the same latitude and season of the year. The relationship between the change in total ozone and air mass agrees with observations made by others within the past 10 years. 
The author expresses appreciation to the Naval Research Laboratory, which sponsored and financed this work at White Sands Proving Ground, N. Mex.; and to R. Tousey, who made the arrangements for this trip, to F. S. Johnson, S. S. Houston, and D. C. Olsen, who assisted in the observational program; and to other members of the White Sands Proving Ground staff who helped to make this work possible.

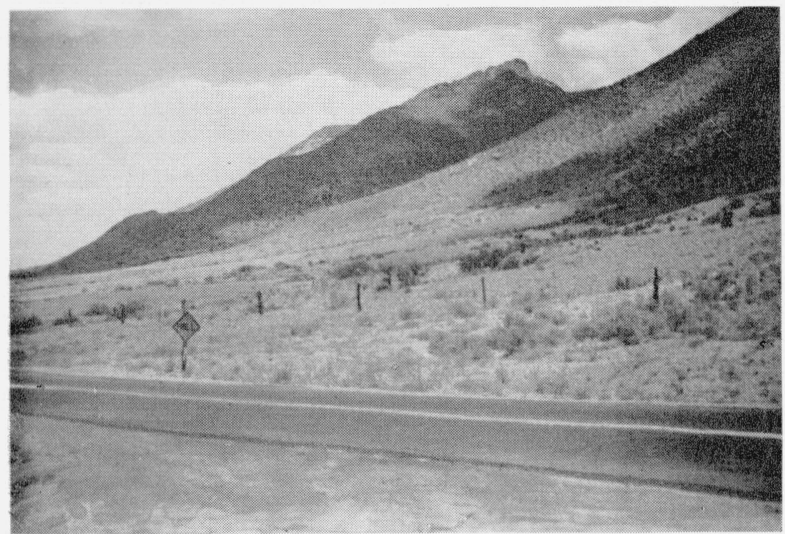

Figure 8. San Augustine Pass, New Mexico, elevation 5,640 feet, looking north; showing clouds, on afternoon of July 3 .

\section{References}

[1] R. Stair and I. F. Hand, Monthly Weather Rev., 67, 331 (1939).

[2] G. M. B. Dobson, Proc. Roy. Soc. (London) [A] 129, 411 (1930).

[3] A. Vassy and E. Vassy, Compt. rend 207, 1232 (1938).

[4] D. Barbier and D. Chalonge, J. phys. radium, 10, 113 (1939).
[5] F. W. P. Götz, Helv. Phys. Acta. 13, p. 3 (1940).

[6] G. M. B. Dobson and A. R. Meetham, Quart. J. Roy. Meteorolog. Soc. (London) 60, 265 (1934).

[7] F. W. P. Götz, Gerlands Beitr. Geophys. 31, 119 (1931).

[8] G. M. B. Dobson, A. W. Brewer, and B. M. Cwilong, Proc. Roy. Soc. (London) [A] 185, 144 (1946).

[9] R. Stair and W. W. Coblentz, J. Research NBS 20, 185 (1938) RP1075.

[10] R. Stair and W. O. Smith, J. Research NBS 30, 449 (1943) RP1543.

[11] R. Stair and W. W. Coblentz, Nat. Geog. Soc., Contr. Tech. Papers, Solar Eclipse Series No. 2, p. 48 (1942).

[12] John Strong, Phys. Rev. 55, 1114 (1939); J. Franklin Inst. 231, 121 (1941); J. Opt. Soc. Am. 29, 520 (1939).

[13] K. Walanabe, J. Franklin Inst. 236, 461 (1943).

[14] W. W. Coblentz and R. Stair, J. Research NBS 16, 315 (1936) RP877.

[15] C. Fabry and H. Buisson, J. Phys. [5] 3, 196 (1913); Astrophys. J. 54, 297 (1921).

[16] B. O'Brien, Nat. Geog. Soc. Contrib. Tech. papers, Stratosphere Series, No. 2, p. 49 (1936).

[17] H. H. Cary and Arnold O. Beckman, J. Opt. Soc. Am. 31, 682 (1941).

[18] Kasson S. Gibson and Margaret M. Balcom, J. Research NBS 38, 601 (1947) RP1798.

[19] The American ephermeris and nautical almanac (Nautical Almanac Office, U. S. Navy Dept. Washington, D. C., 1947).

[20] F. Ball, Altitude tables, $30^{\circ}$ to $60^{\circ}$ (J. S. Potter, London, 1907).

[21] R. Stair and I. F. Hand, Bul. Am. Meteorolog. Soc. 22, 259 (1941).

[22] E. O. Hulburt, The upper atmosphere of the earth, J. Opt. Soc. Am. 37, 405 (1947).

[23] George A. Van Lear, J. Opt. Soc. Am. 37, 525 (1947).

Washington, September 16, 1947. 